Meta

Journal des traducteurs

Translators' Journal

\title{
Bulles en perspective : parcours de la bande dessinée en traductologie
}

\section{Malka Irina Acosta Padilla}

Volume 60, numéro 2, août 2015

$60^{\mathrm{e}}$ anniversaire. Les horizons de la traduction : retour vers le futur $60^{\text {th }}$ Anniversary. Translation's Horizons: Back to the Future

60mo aniversario. Los horizontes de la traducción: regreso al futuro

URI : https://id.erudit.org/iderudit/1032861ar

DOI : https://doi.org/10.7202/1032861ar

Aller au sommaire du numéro

Éditeur(s)

Les Presses de l’Université de Montréal

ISSN

0026-0452 (imprimé)

1492-1421 (numérique)

Découvrir la revue

Citer ce document

Acosta Padilla, M. I. (2015). Bulles en perspective : parcours de la bande dessinée en traductologie. Meta, 60(2), 310-310.

https://doi.org/10.7202/1032861ar d'utilisation que vous pouvez consulter en ligne. 


\title{
Bulles en perspective: parcours de la bande dessinée en traductologie
}

\author{
Malka Irina Acosta Padilla \\ Université de Montréal, Montréal, Canada \\ malka.acosta@gmail.com
}

La bande dessinée ou le $9^{\mathrm{e}}$ art, comme elle est connue de nos jours, a fait son apparition à la fin du XIX ${ }^{e}$ siècle en Europe et aux États-Unis. Elle s'est ensuite répandue dans le monde entier, au point de devenir un moyen d'expression présent dans les cinq continents. Or, c'est grâce à la traduction que les comics américains, la $\mathrm{BD}$ franco-belge et le manga japonais ont traversé les frontières.

Toutefois, la bande dessinée a été longtemps négligée par le monde académique. Ce n'est qu'à partir des années 1980 que diverses disciplines en font leur objet d'études, y compris la traductologie. Dans les trois dernières décennies, les traductologues ont abordé la traduction de la bande dessinée sous des angles très variés, souvent privilégiant le contenu verbal des œuvres sans tenir compte du contenu visuel.

Dans la présente recherche, nous nous proposons, en premier lieu, de retracer le parcours de la bande dessinée dans la traductologie en mentionnant les principales approches utilisées. Ensuite, nous présenterons l'approche la plus récente employée pour l'étude de la bande dessinée, la multimodalité. Après avoir discuté les travaux de Klaus Kaindl (2004) et de Michel Borodo (2015), nous présenterons notre modèle pour l'étude de la multimodalité en BD adapté de l'analyse textuelle de Hatim et Mason (1990, 1997).

Malka Irina Acosta Padilla détient un DESS en traduction anglais-français de l'Université de Montréal. Actuellement, elle est candidate à la maîtrise en traduction dans la même université. Elle a présenté les résultats de sa recherche au XXIII Encuentro Internacional de Traductores Literarios à Mexico et au XVIII Congrès de l'Association canadienne de traductologie (ACT) à Ottawa. Ses domaines d'intérêt sont la traduction de l'humour, les textes multimodaux et leur traitement en traduction et la traduction des bandes dessinées. Actuellement, elle travaille comme assistante de recherche dans le groupe HISTAL de l'Université de Montréal. 